\title{
CONF 9210339
}

\section{Photodetachment Studies on Few-Electron Atomic Negative Ions}

\author{
David J. Pegg \\ Department of Physics, University of Tennessee, \\ Knoxville, Tennessee 37996
}

\section{Introduction}

A crossed laser-negative ion beams apparatus, situated at Oak Ridge National Laboratory, has been used for energy-and angle-resolved photoelectron spectroscopic measurements following photodetachment. In the current grant period measurements of the cross sections for photodetaching an electron from the $\mathrm{Li}^{-}$ion were finished. Measurements of the $\sigma\left(\mathrm{B}^{-}\right) / \sigma\left(\mathrm{Li}^{-}\right)$ ratio, with a goal of determining photodetachment cross sections for $\mathrm{B}^{-}$, were started. An investigation of the photodetachment of the metastable ion $\mathrm{Be}^{-}$also began. Preliminary data on the electron affinity, asymmetry parameter and cross section associated with the photodetachment of $\mathrm{Be}^{-}$at a photon energy of $2.076 \mathrm{eV}$ is reported.

\section{Cross Sections}

The cross section ratio, $\sigma\left(\mathrm{Li}^{-}\right) / \sigma\left(\mathrm{D}^{-}\right)$, was measured to be $1.98 \pm 0.15,1.84 \pm 0.11$ and 2.97 \pm 0.28 at photon energies of $1.871,2.077$ and $2.442 \mathrm{eV}$, respectively. An absolute scale for these measurements was established by normalizing the measured ratios to theoretical $\sigma\left(\mathrm{H}^{-}\right)$cross sections, which are known to better than $3 \%$. The measured absolute cross sections, $\sigma\left(\mathrm{Li}^{-}\right)$, at the same photon energies quoted above, are $73.5 \pm 6.0,63.5 \pm 5.7$ and $89.8 \pm 9.5 \mathrm{Mb}$, respectively. These values are consistently lower than the accepted theoretical predictions ${ }^{1}$ by about $10 \%$, which is also the estimated uncertainty on both the experimental and theoretical results. Since $\sigma\left(\mathrm{Li}^{-}\right)$is large a detailed investigation of the saturation characteristics of $\mathrm{Li}^{-}$and $\mathrm{D}$ photodetachment was made.The results are shown in Fig. 1. The fitted curves can be used to extract an apparent cross section ratio at each laser power and this

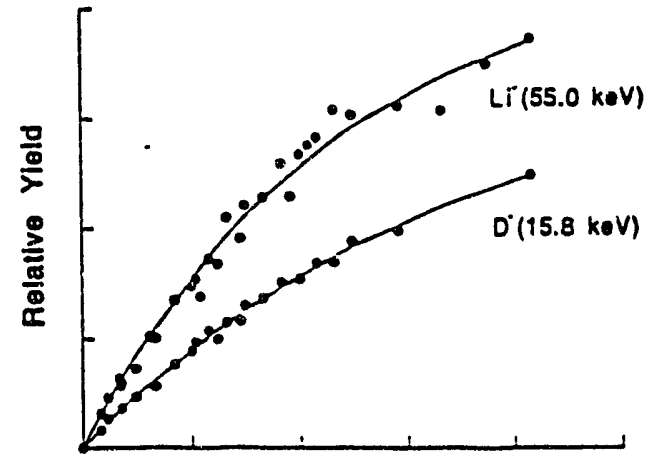

Relative Laser Power ratio can be extrapolated to zero laser power to yield a Fig. 1 Saturation curves for $\mathrm{Li}^{-}$and $\mathrm{D}^{-}$-photodecachment. ratio of 1.86 . This result is consistent with the measured value of $1.84 \pm 0.11$ obtained by acquiring datasolely in the unsaturated regime i.e. where there exists, to a good approximation, a linear dependence on the photon flux. The photodetachment of $\mathrm{Li}^{-}$forms the subject matter of the Ph.D. thesis of Joseph Dellwo. The cross section for photodetaching $B^{-}$via the process $h v+B^{-}\left({ }^{3} P\right) \rightarrow B\left({ }^{2} P\right)+e^{-}(\epsilon s, d)$ has not been previously measured or calculated. We made earlier measurements of the asymmetry parameter for this process at several discrete photon energies in the visible.. A program to determine $\sigma\left(\mathrm{B}^{-}\right)$via $\sigma(\mathrm{B}$ $\left.{ }^{-}\right) / \sigma\left(\mathrm{Li}^{-}\right)$ratio measurements has begun. A preliminary result, at a photon energy of $2.077 \mathrm{eV}$, is $0.33 \pm 0.03$. Using our previously measured $\sigma\left(\mathrm{Li}^{-}\right)$result for normalization yields an absolute value of $\sigma\left(\mathrm{B}^{-}\right)=21 \pm 3 \mathrm{Mb}$.

\section{MASTER}

DISTRIBUTION BF THIS DOCUMENT IS UNLIMTIED 
A preliminary measurement of the ratio $\sigma\left(\mathrm{Be}^{-}\right) / \sigma\left(\mathrm{D}^{-}\right)$has also been made. At a photon energy of $2.076 \mathrm{eV}$ the ratio is found to be $0.22 \pm 0.04$, corresponding to an absolute cross section, $\sigma\left(\mathrm{Be}^{-}\right)=7.5 \pm 1.3 \mathrm{Mb}$ when a theoretical value of $\sigma\left(\mathrm{H}^{-}\right)$is used for normalization. In these experiments the $\mathrm{Be}^{-}$ion is formed in the metastable state $\left(1 \mathrm{~s}^{2} 2 \mathrm{~s} 2 \mathrm{p}^{2}\right){ }^{4} \mathrm{P}$ and photodetachment proceeds via the reaction $h v+\mathrm{Be}^{-}\left({ }^{4} \mathrm{P}\right) \rightarrow \mathrm{Be}\left({ }^{3} \mathrm{P}\right)+\mathrm{e}^{-}(\epsilon \mathrm{s}, \mathrm{d})$.

\section{Asymmetry Parameter}

Photoelectron yields obtained from energy-and angle-resolved spectroscopic measurements are proportional to differential cross sections. To determine an angle-integrated partial cross

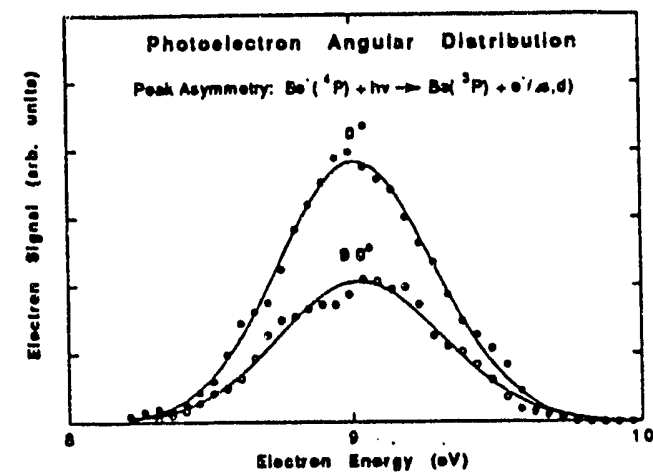

Fig. 2 Photodetachment of Be-: photoelectron yields for horizontal (upper) and vertical (lower) laser polarization. section it is necessary to measure, in addition, the angular distribution of the photoelectrons. The shape of these emission patterns is characterized by an asymmetry parameter $B$, which measures the deviation from isotropy. We report here the first measurement of the angular distribution of electrons photodetached from the metastable $\mathrm{Be}^{-}$ion. At a photon energy of $2.076 \mathrm{eV}$, the experiment yielded a preliminary result of $\beta=0.41 \pm 0.04$. Fig. 2 illustrates the peak asymmetry i.e., the change in photoelectron yield when the linear polarization vector of the laser beam is rotated from horizontal $\left(\theta=0^{\circ}\right.$, parallel to electron emission direction) to vertical $\left(\theta=90^{\circ}\right.$, perpendicular to the emission direction). The value of $B$ in this case is determined by an interference between the $s$ and $d$ waves representing the ejected electron.

\section{Electron Affinity}

We also report the first photodetachment measurement of the electron affinity of the $\mathrm{Be}\left(2^{3} \mathrm{P}\right)$ atom. This was achieved by comparing the electron spectra (see Fig. 3 ) resulting from the photodetachment of $\mathrm{Be}^{-}\left({ }^{4} \mathrm{P} \rightarrow{ }^{3} \mathrm{P} \epsilon \mathrm{S}, \mathrm{d}\right)$ and $\mathrm{He}^{-}\left({ }^{4} \mathrm{P} \rightarrow\right.$ ${ }^{3} \mathrm{P} \in \mathrm{p}$ and $\left.{ }^{4} \mathrm{P} \rightarrow{ }^{3} \mathrm{~S} \in \mathrm{S}, \mathrm{d}\right)$ ions taken at a common ion beam energy of $45.46 \mathrm{keV}$. The known separation of the $\mathrm{He}^{-}$ peaks in the ion rest frame i.e. the energy difference between the $2^{3} \mathrm{~S}$ and $2^{3} \mathrm{P}$ leveis in $\mathrm{He}$ allowed us to accurately determine the ion beam energy in situ. A measurement of the separation of the $\mathrm{Be}^{-}$peak and either of the $\mathrm{He}^{-}$peaks permitted us to determine the electron affinity of Be. Our preliminary electron affinity result is $260 \pm 30 \mathrm{meV}$ which appears to confirm the most accurate calculated value $\mathrm{e}^{3}$ of $276.1 \pm 6.5 \mathrm{meV}$. We

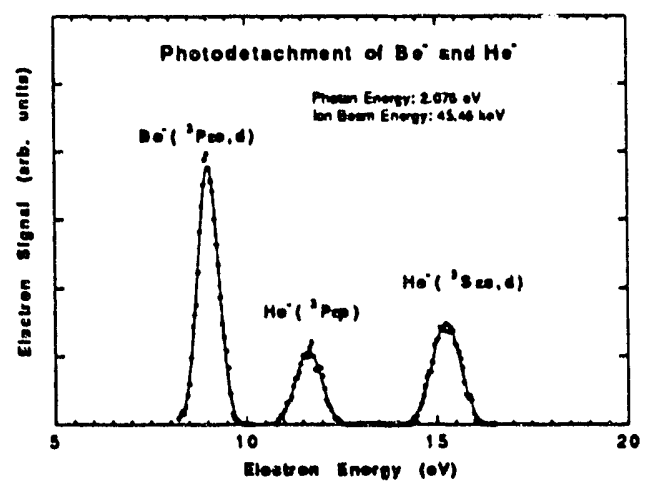
hope of to improve on the precision of the measurement Fig. 3 Photodetachment electron spectra of Be- and He- ions. in the future. The only other measurement of this quantity yielded a value of $190 \pm 110 \mathrm{meV}$. This lower precision result was obtained by autodetachment spectroscopy. ${ }^{4}$ 


\title{
Future Plans
}

We propose to continue our measurements of cross sections for the photodetachment of an electron from $\mathrm{B}^{-}$and $\mathrm{Be}^{-}$ions at discrete photon energies across the visible spectrum. The work will also involve an investigation of the spectral dependence of the asymmetry parameters.

\section{References}

1. D. Moores and D. Norcross, Phys. Rev. A1ㅡ, 1646 (1974); R. Moccia and P. Spizzo, J. Phys. B 23,3557 (1990).

2. Y. Liu, D. J. Pegg, J. S. Thompson, J. Dellwo and G. D. Alton, J. Phys. B24, L1 (1991).

3. A. V. Bunge, Phys. Rev. A33, 82 (1986).

4. T. J. Kvale, G. D. Alton, R. N. Compton, D. J. Pegg and J. S. Thompson, Phys. Rev. Lett. $\underline{55} 484$ (1985).

\section{Recent Publications}

1. "Photodetachment Cross Sections for Li-," J. Dellwo, Y. Liu, C. Y. Tang, D. J. Pegg and G. D. Alton, Phys. Rev. A (to be published).

2. "Near-Threshold Photodetachment of the $\mathrm{Li}^{-}$Ion," J. Dellwo, Y. Liu, D. J. Pegg and G. D. Alton, Phys. Rev. A45, 1554 (1992).

3. "Correlation in Photodetachment," D. J. Pegg in Atomic and Molecular Phvsics, edited by C. Cisneros, I. Alvarez and T. Morgan (World Scientific, Singapore, 1991), p. 348.

4. "Photodetachment of Metastable $\mathrm{He}^{-}, "$ J. S. Thompson, D. J. Pegg, J. Dellwo, R. N. Compton and G. D. Alton, Nucl. Instr. Meth. B56/57, 211 (1991).

5. See reference 2 above.

\section{DISCLAIMER}

\begin{abstract}
This report was prepared as an account of work sponsored by an agency of the United States Government. Neither the United States Government nor any agency thereof, nor any of their employees, makes any warranty, express or implied, or assumes any legal liability or responsibility for the accuracy, completeness, or usefulness of any information, apparatus, product, or process disclosed, or represents that its use would not infringe privately owned rights. Reference herein to any specific commercial produci, process, or service by trade name, trademark, manufacturer, or otherwise does not necessarily constitute or imply its endorsement, recommendation, or favoring by the United States Government or any agency thereof. The views and opinions of authors expressed herein do not necessarily state or reflect those of the United States Government or any agency thereof.
\end{abstract}



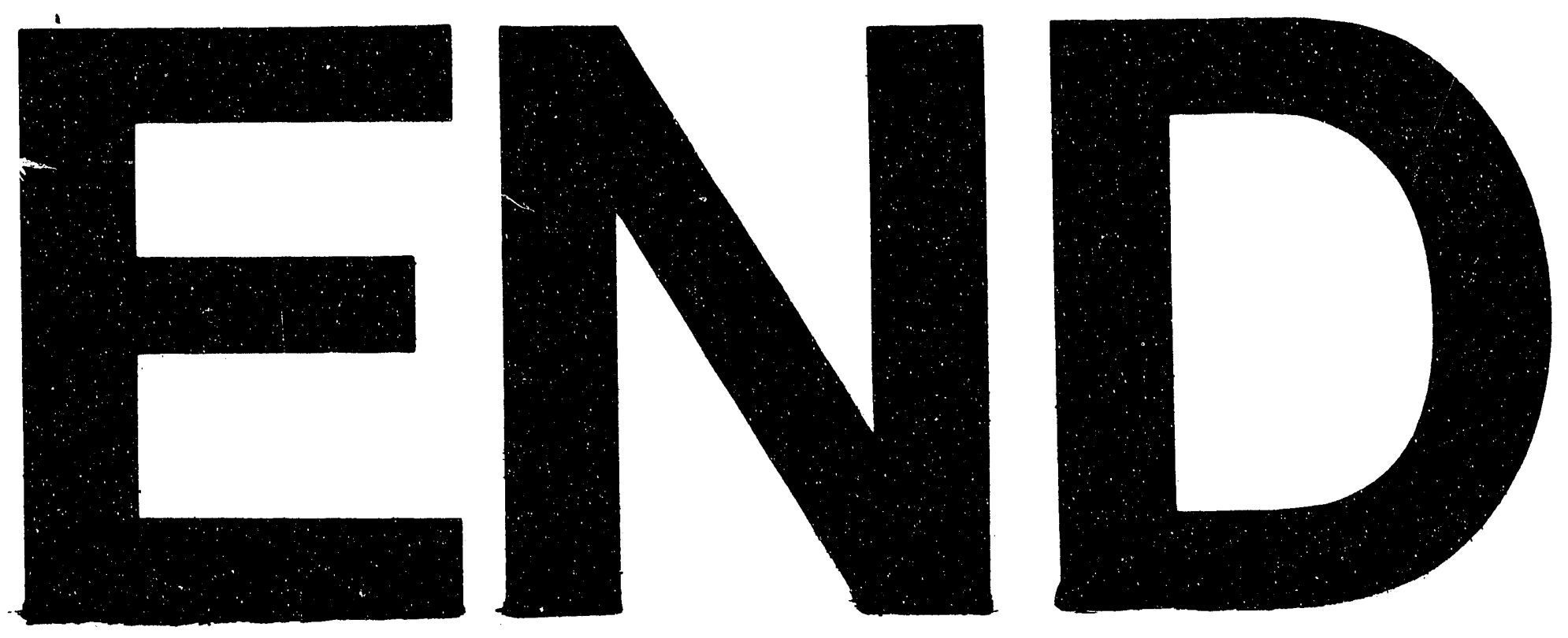

28

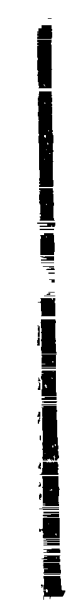
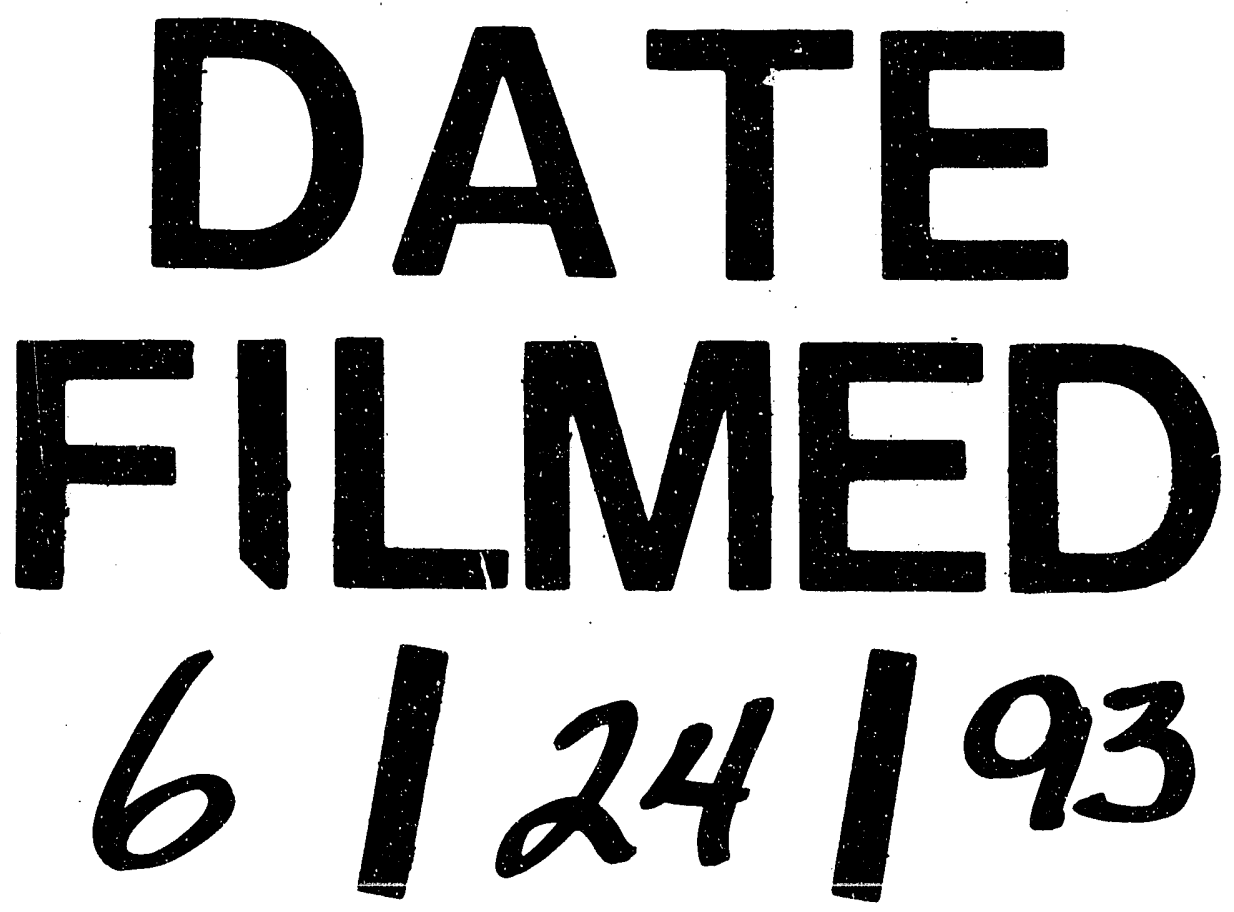
1 